\title{
ALLGEMEINE LITERATUR UBER DIE BULGARISCHE VOLKSKUNDE
}

1 G. P. Ajanov, Strandža. Etnografski, geografski i istoričeski proučvanija. Sofia, 1938, $269 \mathrm{~S}$.

2 R. Angelova, Selo Raduil, Samokovsko. ISSF VIII-IX (1948), S. 131-410.

3 M. Arnaudov, Die bulgarischen Festbräuche. Leipzig, 1917, VIII + 82 S.

4 M. Arnaudov, Studii vъrchu bъlgarskite obredi i legendi I-II. Sofia, 1924, 548 S. +1 Taf. +1 Karte.

5 M. Arnaudov, $1 z$ minaloto na Kotel. GSU XXVII (1931), $100 \mathrm{~S}$.

6 M. Arnaudov, Očerki po bolgarskija folklor. Sofia, 1934, 695 S.

7 1. Basanovič, Materiali za sanitarna etnografija na Bzlgarija. Lomskijat okrъg (18801889). SbNU V (1891), S. 3-186.

8 N. Chajtov, Selo Javrovo, Asenovgradsko, Sofia, 1958. 246 S. +52 Taf.

9 N. Chajtov, Asenovgrad v minaloto, Sofia, 1965. 416 S. +30 Taf.

10 P. Cončev, Iz stopanskoto minalo na Gabrovo. Sofia, 1929, $636+$ XXXVIII S.

11 V. Dečev, Minaloto na Cepelare I. Sofia, 1928, VI + 303 S. + 42 Taf.; II. Sofia, 1936, $\mathrm{XI}+464$ S. + 45 Taf.

12 N. S. Deržavin, Bolgarskie kolonii v Rossii. (Tavričeskaja, Chersonskaja i Besarabskaja gubernii). Materiali po slavjanskoj etnografii. SbNU XXIX (1914), XII + 259 S. + CXCVIII Taf.

13 S1. Dičev - N. Chajtov, Selo Manastir, Smoljansko. Sofia, 1965, 198 S.

14 P. Dinekov, Bzlgarski folklor, čast I. Sofia, 1959, $586 \mathrm{~S}$.

$15 \mathrm{Kr}$. Drončilov, Burel. Antropogeografski izučvanija. GSU XIX (1923), 250 S. + XXIV Taf.

16 G. Gunčev, Vakarel. Antropogeografski proučvanija. GSU XXIX-8 (1933), 188 S. + VIII Taf.

17 K. Jireček, Knjažestvo B̋lgarija - negovata povъrchnina, priroda, naselenie, duchovna kultura $i$ novejša istorija. Cast I, Plovdiv, 1899, VIII + 430 S.; Cast II, Plovdiv, 1899, XXIII + 943 S.

18 P. T. Karapetkov, Slaveino. Minalo. Plovdiv, 1948. 545 S.

19 V. Kъnčev, Velikdenska razchodka po Poleninsko. SbNU IX (1893), S. 647-715.

20 V. Kъnčev, Prtuvane po dolinite na Struma, Mesta i Bregalnica. SbNU X (1894), S. 469535; XI (1894), S. 195-250; XII (1895), S. 212-317; XIII (1896), S. 323-354.

21 D. Konstantinov, Zeravna $v$ minaloto $i$ do dnešno vreme. Sofia, 1948, $512 \mathrm{~S}$.

22 St. L. Kostov - E. Peteva, Selski bit $i$ izkustvo v Sofijsko. Sofia, 1935, IV + 207 S. + XXXIV Taf.

23 D. Marinov, Živa starina I, Ruse, 1891, XX + 189 S.; II. Ruse, 1892, XVI + 306 S.; III, Ruse, 1892, X + 383 S.; IV, Ruse, 1894, 540 S. 
24 D. Marinov, Gradivo za veštestvenata kultura na Zapadna Bøolgarija. SbNU XVIII (1901), $201 \mathrm{~S}$.

25 D. Marinov, Narodna vjara $i$ religiozni narodni običai. SbNU XXVIII (1914), VIII + 574 S. + XXXIV Taf.

26 Fr. Miklosich, Lexicon palaeoslovenico-graeco-latinum. Emendatum auctum. Vindobonae, 1862, XXII + $1171 \mathrm{~S}$.

27 St. Mladenov, Etimologičeski i pravopisen rečnik na bъlgarskija knižoven ezik. Sofia, 1941, $\mathrm{XX}+704 \mathrm{~S}$.

28 K. Moszyński, Kultura ludowa Slowian: cz. I, Kraków, 1929. IX +719 S.; cz. II, zesz. 1, Krak6w, 1934, 722 S.; zesz. 2, Kraków, 1939, VII + 723-1642 S.

29 T. Petrov, Izloženie za sanitarnoto $i$ ikonomičesko szstojanie na Orchanijska okolija prez 1902 i 1903 godina. SbNU XXI (1905), $78 \mathrm{~S}$.

30 G. S. Rakovski, Pokazalec ili rokovodstvo kak da sja iziskvъt $i$ izdirjot naj-stari čbrti našego bitija ... Odessa, 1859, $144 \mathrm{~S}$.

31 Cv. Romanska-Vranska, Bə̌lgarsko narodno poetičesko tvorčestvo. Hristomatija. Sofia, 1958, $251 \mathrm{~S}$.

32 Iv. Sakazov, Bulgarische Wirtschaftsgeschichte. Berlin-Leipzig, 1929, IX + 294 S.

33 A. M. Seliščev, Slavjanskoe naselenie v Albanii. Sofia, 1931, 352 S. + 1 Karte.

34 St. N. Siškov, Izbrani proizvedenija. Plovdiv, 1965, 422 S.

35 S. Tabakov, Istorija na grad Sliven, t. II, Sofia, 1924, 605 S.; t. III, Sofia, 1929, 352 S.

36 G. Tašev, Selo Petkovo. Sofia, 1966, 376 S.

$37 \mathrm{~K}$. Telbizov i M. Vekova-Telbizova, Tradicionen bit $i$ kultura na banatskite bəlgari. SbNU LI (1963), $362 \mathrm{~S}$.

$38 \mathrm{~J}$. Trifonov, Svedenija iz starobolgarskija život $v$ Šestodneva na Joan Ekzarcha. SpBAN XXXV-19 (1926), S. 1-36.

39 Chr. Vakarelski, Bit na trakijskite i maloazijskite bolgari. Sofia, 1935, VIII + 496 S. $+\mathrm{V}$ Taf.

$40 \mathrm{Chr}$. Vakarelski, Njakolko kulturni $i$ ezikovi granici $v$ Bolgarija. IBGD II (1935), S. $58-100$.

41 Chr. Vakarelski, Note sur l'éthnographie des bulgares. La Bulgarie devant le IVe Congrès des géographes et ethnographes slaves. Sofia, 1936, S. 121-159.

$42 \mathrm{Chr}$. Vakarelski, Starinnite elementi v brlgarskite narodni običai. Sb. Prez vekovete, Sofia, 1938, S. 246-281.

43 Chr. Vakarelski, Bəlgarski praznični običai. Sofia, 1943, $132 \mathrm{~S}$.

$44 \mathrm{Chr}$. Vakarelski, Bitovata veštestvena kultura $v$ Dobrudža $i$ promenite $v$ neja prez poslednite desetiletija. SbDE, 1956, S. 207-256.

$45 \mathrm{Chr}$. Vakarelski, Prinos kъm tradicionnija bit i tradicionnata kultura na Panagjursko. PP I, 1956, S. 67-144.

46 Chr. Vakarelski, Veštestvenata kultura v Strandžanskata oblast. SbSE, 1958, S. 207-256.

47 Chr. Vakarelski, Kratki beležki po etnografija na brlgarite. Sofia, čast I, 1959, 32 S., čast II, 1959, $28 \mathrm{~S}$.

$48 \mathrm{Chr}$. Vakarelski, Prinos kъm proučvane na semejnite običai na Panagjursko $v$ minaloto. PP II, 1961, S. 53-85. 
$49 \mathrm{Chr}$. Vakarelski, Charakteristische Merkmale der bäuerlichen Volkskultur in Bulgarien. Südosteuropa-Jahrbuch, München, Bd. VI, 1962, S. 125-133 + 4 Taf.

$50 \mathrm{Chr}$. Vakarelski, Dobrudža. Materiali kъm veštestvenata kultura na bъlgarite prez perioda na kapitalizma. Sofia, 1964, 240 S.

51 N. Vrančev, Brolgari mohamedani (pomaci). Sofia, 1948, $63 \mathrm{~S}$.

52 J. Zachariev, Kjustendilsko Krajste. SbNU XXXII (1918), XXV + 653 S. + LXIX + IV Taf.

53 J. Zachariev, Kamenica. SbNU XL (1935), 458 S. + XLVIII + XII Taf.

54 J. Zachariev, Pijanec. SbNU XLV (1949), VIII + 423 S. + LXX Taf.

55 J. Zachariev, Kjustendilskata kotlovina. Geografsko-etnografsko izučvane. Sofia, 1963, $426 \mathrm{~S}$. 
